
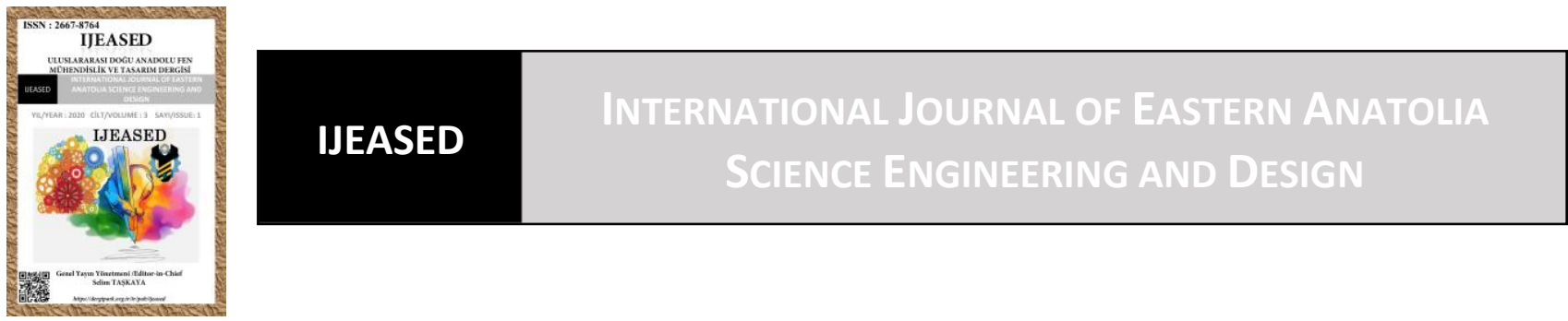

\author{
Uluslararası Doğu Anadolu Fen Mühendislik ve Tasarım Dergisi \\ ISSN: 2667-8764, 3(1), 43-54, 2021 \\ https://dergipark.org.tr/tr/pub/ijeased
}

Araştırma Makalesi / Research Article

Doi: $\underline{10.47898 / \text { ijeased.814138 }}$

\title{
Karabük Kent Meydanı'ndaki “Meydan” Deneyimini Mekan Dizimi Yöntemi ile Değerlendirme
}

\author{
Ayşe Merve SARAÇOĞLU GEZER ${ }^{1 *}$, Bahar SULTAN QURRAIE ${ }^{1}$
}

${ }^{1}$ Karabük Üniversitesi, Mimarlık Fakültesi, Mimarlık Bölümü, Karabük, 78600, Türkiye.

\begin{tabular}{l|l|l}
\hline \multicolumn{1}{c|}{ Yazar Kimliği / Author ID (ORCID Number) } & \multicolumn{1}{|c}{ Makale Süreci / Article Process } \\
\hline "Sorumlu Yazar / Corresponding author : & Geliş Tarihi / Received Date $:$ & 21.10 .2020 \\
mervesaracoglu@karabuk.edu.tr & Revizyon Tarihi / Revision Date : & 05.12 .2020 \\
\hline iD https://orcid.org/0000-0001-6326-5151, M. S. Gezer & Kabul Tarihi / Accepted Date : & 02.01 .2021 \\
iD $\underline{\text { https://orcid.org/0000-0002-5142-3367, B. S. Qurraie }}$ & Yayım Tarihi / Published Date : & 15.07 .2021 \\
\hline
\end{tabular}

Alıntı / Cite : Gezer, M.S., Qurraie, B.S. (2021). Karabük Kent Meydanı'ndaki “Meydan” Deneyimini Mekan Dizimi

Yöntemi ile Değerlendirme, Uluslararası Doğu Anadolu Fen Mühendislik ve Tasarım Dergisi, 3(1), 43-54.

Özet

Kent meydanları, insanların ortak kullanabildiği, serbestçe dolaşabildiği, buluşma, birleşme ve kesişme noktası olarak seçtiği tanımlı kentsel boşluklardır. Tanımlı olma durumu kent meydanının etrafında onu sınırlayan öge, obje ya da nesnelerle belirlenir. Yapılarla sınırlanmanın haricinde karayolu, demiryolu, nehir, deniz gibi yapılı ya da doğal çevreyle de sınırları belirlenmiş olabilir. Meydan kentsel bir boşluktur; tanımlı bir mekan olabilmesi için bu boşluğun da tanımlı olması beklenir. Bu çalışmada etrafı yollarla çevrili, kentin/şehrin girişine yakın bir konumda yer alan, içerisine sosyal ve kamusal işlevler de dahil edilmiş bir kent meydanı olan, Karabük Kent Meydanı incelemesi yapılmıştır. Bu inceleme Space Syntax depthMapX programı kullanılarak mekan dizimi yöntemi ile desteklenmiş, programın analiz çıktılarıyla alan araştırmaları çakıştırılmıştır. Çalışma, Karabük Kent Meydanı’nı meydan kavramı üzerine ele almak ve elde edilen verilerle bu meydanı tanımlamayı hedeflemiştir.

Anahtar Kelimeler: Kent Meydanı, Karabük, Mekan Dizimi, depthMapX.

\section{Evaluating The "Square" Experience In Karabük City Square With The Space Syntax Method}

\section{Abstract}

City squares are defined urban spaces that where people can use as a communal area, walk around freely and choose as meeting, merging and crossing place. The state of being defined is determined by the item, object or things that limit 
Gezer, M.S., ve Qurraie, B.S., Uluslararası Doğu Anadolu Fen Mühendislik ve Tasarım Dergisi / International Journal of Eastern Anatolia Science Engineering and Design (IJEASED)

(2021) 3(1):43-54

it around the city square. Apart from being limited to buildings, borders may also be determined with the built or natural environment such as road, rail, river, sea. The square is an urban void; to be a defined space, this space is expected to be defined. In this study, the study of Karabük City Square, which is a city square surrounded by roads, located close to the entrance of the city, including social and public functions, was conducted. This review was supported by the space syntax method using the Space Syntax depthMapX program, and the field studies were overlaid with the analysis outputs of the program. The study aimed to handle Karabük City Square on the concept of the square and to define this square with the data obtained.

Keywords: City square, Karabuk, Space syntax, depthMapX.

\section{Giriş}

Meydanlar, insanların çeşitli amaçlarla bir araya gelebileceği, buluşabileceği, toplanabileceği ya da etkinlikler yapabileceği, etrafında sınırlayıcı ya da belirleyici ögelerin olduğu kent içindeki kamusal alanlardır. En basit anlamıyla bir 'alan' olarak tanımlanabilen meydanları, Hasol (2017) "halkın toplandığı, çoğu binalarla, ağaçlarla ya da doğal engellerle çevrili, düz, açık ve geniş yer" olarak açıklamaktadır. Kamusal olması, halka ait, erişilebilir ve ulaşılabilir olması, meydanın devinime sahip bir alan olabilmesi için önemli faktörlerdir ve bunlar meydanın fiziki özelliklerinin sonuçları olarak karşımıza çıkmaktadır. Meydanlar, kentin içinde, kentin hareketine ya da yoğunluğuna rağmen, insanların nefes alabileceği, durup soluklanabileceği ya da harekete geçip stres atabileceği alanlar olarak görülmelidir.

Meydanların, kent ve kentli için her zaman önemli bir yeri vardır. Eski kent örneklerinde de kentin içinde, kamusal alan olarak izleri okunabilen, toplanma işlevi ve karar alma mekanizmalarını hayata geçiren meydanlar ayırt edilebilmektedir. $\mathrm{Bu}$ yönüyle, kent için olumlu katkılar sağladığ söylenebilmektedir (Ulutaş, 2019). Bir yerin insanların kullanımında olması, o yerin hala yaşadığını, yaşatılacağını ve bir biçimde korunduğunu da göstermektedir. Bu açıdan bakıldığında, bir kentin deviniminin sağlanabilmesi için de meydanlar gibi özellikle kamusallı̆̆ın ön plana çıktığı, kentsel mekanların ne kadar önemli oldukları daha iyi anlaşılmaktadır.

1995 yılında Türkiye'nin 78. ili olma statüsüne yükselen Karabük ilinin de böyle bir meydana ihtiyacı olduğu düşünülmüş ve kent için en uygun olduğu düşünülen alana Karabük Kent Meydanı inşa edilmesine karar verilmiştir. Bu kararla birlikte kentlinin önemsediği günler, etkinlikler, aktiviteler ya da programlar için bir araya gelebileceği bir toplanma alanı oluşturulmuştur. Ancak meydanın kavramsal altyapısında yalnızca belirli günlerde kullanılması değil, kentlinin herhangi bir zamanda serbest dolaşımda da tercih etmesi bulunmaktadır. Karabük Merkez'de yer alan bu meydan için ikinci seçeneğin zayıf bir etkide süregeldiği düşünüldüğünden, bu çalışmada meydanın 
çok yönlü olarak incelenmesi ve mekan dizim analizi ile birlikte konumunun ve planının irdelenmesi planlanmıştır.

\subsection{Karabük, Kentleşme ve Kent Meydanı İlişkisi}

Karabük, 1937 yılına kadar Safranbolu'nun Öğlebeli köyüne ait bir mahalledir. On üç haneli bir yerleşim olduğu da bilinmektedir (Kütükçüoğlu, 2012). 1932 yılında bu yerleşmeye iki kilometre mesafede bir istasyon kurulması kararı alınmıştır. $\mathrm{Bu}$ istasyon, Erken Cumhuriyet Dönemi'nde hayata geçirilen demiryolu hatlarının bir kolu olan Ankara-Zonguldak hattına ait küçük bir istasyondur. İstasyona da mahallenin adı olan 'Karabük' adının verilmesiyle, bu ad ilk kez resmi kayıtlara geçmiştir (Fındıkoğlu, 1960).

Karabük'ün gelişmesindeki en önemli faktör olan Karabük Demir Çelik Fabrikası'nın kurulmasına Aralık 1934 yılında karar verilmiştir. 1935 yılında ise İngiliz bir firma olan Brassert, Sümerbank ile anlaşma sağlayarak KDÇF’nin temelleri 3 Nisan 1937 yılında atılmıştır (Kalyoncu, 2016). Fabrikadan önce yerleşim yeri olarak yalnızca on üç haneden oluşan bir köy olarak bahsedilen Karabük, fabrikadan sonra Sümerbank’ın fabrikaya bağlı konut üretimi çalışmalarıyla gelişmeye başlamıştır. Fabrikalarda çalışacak işçiler için gerekli olan tüm ihtiyaçlar bu sayede karşılanacaktır. En temel ihtiyaç olan barınma ihtiyacını karşılamanın dışında sosyal, kültürel, fiziksel ve eğitim yapıları da modernleşme ve endüstrileşme politikalarına bağlı olarak inşa edilmiştir.

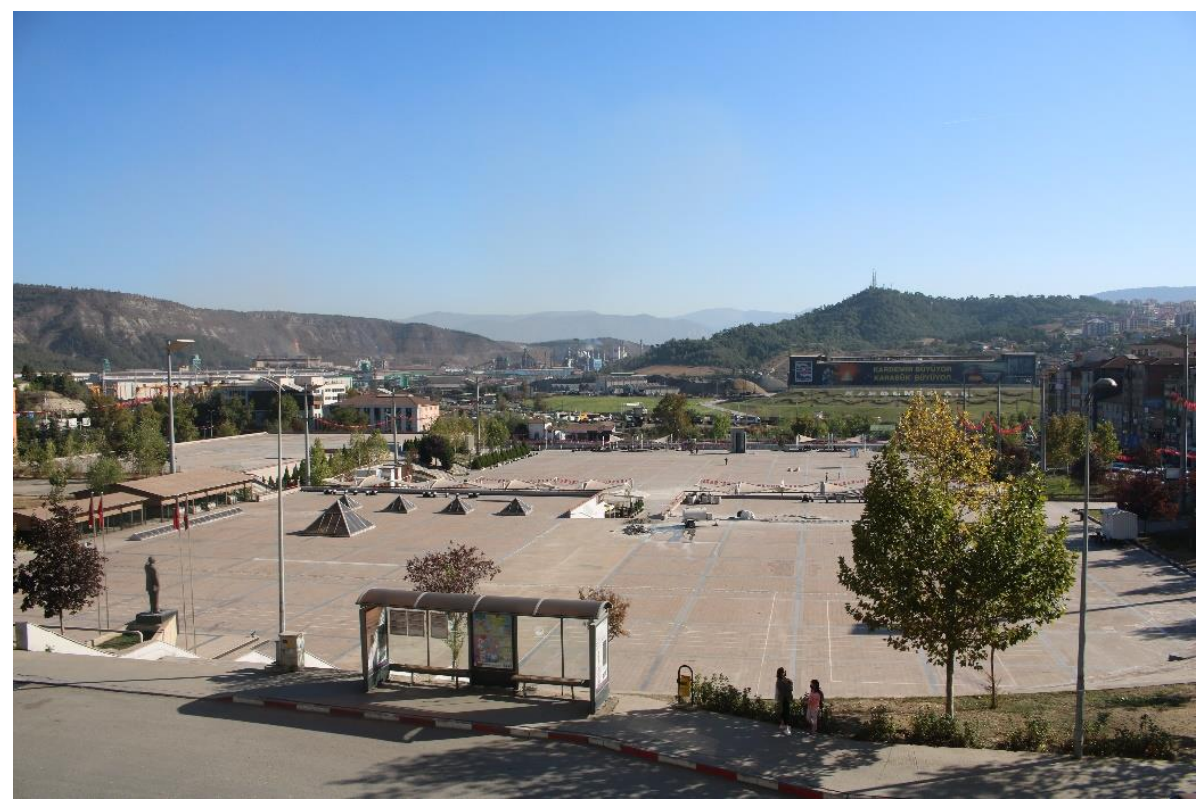

Şekil 1. Karabük Kent Meydanı ve Kardemir Demir-Çelik Fabrikası 
Gezer, M.S., ve Qurraie, B.S., Uluslararası Doğu Anadolu Fen Mühendislik ve Tasarım Dergisi / International Journal of Eastern Anatolia Science Engineering and Design (IJEASED)

(2021) 3(1):43-54

Karabük ili Merkez ilçesinde bulunan 'Karabük Kent Meydanı’ da şehrin girişinde, görünür ve ulaşılabilir bir mevkide yer almaktadır (Şekil 1). Bu meydan inşa edilmeden önce şehrin 'meydan' olarak tanımlanabilecek bir alanı olmadığından, Karabük için 'her şeyin başladığı yer' olan İstasyon binası ve çevresi bu işlevi görmekteydi. İstasyon ve çevresi kent için önemli bir yere sahiptir. Toplanma ve dağılma mekanı, bir buluşma noktası, kavuşma ve vedalaşma yeridir. 2015 yılına kadar İstasyon ve çevresi bu 'meydan' işlevini üstlenmişken, kentin yeni bir meydana ihtiyacı olduğu düşünülmüş ve 'Kent Meydanı' inşa edilmiştir. Bu meydan için Karabük Demir-Çelik Fabrikalarına ait konut yerleşkelerinden biri olan 100 Evler'in yıkılmasına karar verilmiştir. Ortaya çıkan kentsel boşluk meydan olarak değerlendirilmiştir.

Karabük Kent Meydanı bünyesinde nikah salonu, kafe ve dükkanlar, bir amfi tiyatro oturma düzeni, belediyeye ait bir kiosk ve birkaç pergola bulunmasına rağmen günlük yaşam içinde kullanımı düşüktür. Yazın güneşten korunacak yeterli gölgelik alan barındırmaması, kışın da rüzgardan koruyacak engeller olmaması nedeniyle insanlar tarafından sosyalleşme amaçlı kullanılamamaktadır. Yılın belli dönemlerinde belediye destekli kermes faaliyetleri ya da indirim günleri kapsamında kurulan KOBİ destek çadırlarıyla canlandırılmaya çalışılmaktadır. Halk konserleri, mitingler, şehit cenazeleri ve benzeri kalabalık toplantılar için de ev sahipliği yapmaktadır. Ancak bu tip etkinliklerin bir yıllık periyot içinde ne kadar az olduğu da göz önünde bulundurulmalıdır.

Varolan bir mekanın dönüştürülmesi ve mevcut topografyanın şartlarına uyma eğilimi nedeniyle Karabük Kent Meydanı kot farkları olan bir meydandır. Merdivenler, basamaklar ya da rampalar ile kademelenme uygulanmış, her kot farklı bir işleve hizmet edecek şekilde inşa edilmiştir. Ortaya çıkan kot farkının bir kısmı da amfi tiyatro olarak değerlendirilmiştir (Şekil 2).

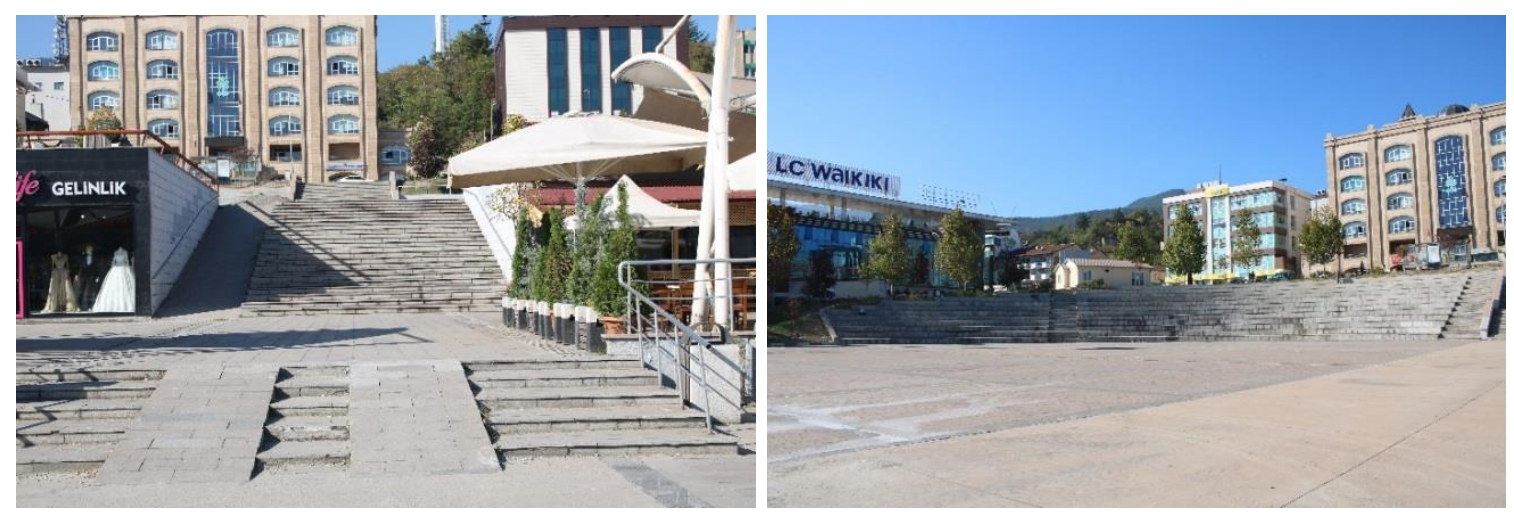

Şekil 2. Karabük Kent Meydanı merdivenleri ve amfi tiyatro 


\section{Materyal ve Metot}

Bu çalışma, Karabük Kent Meydanı'nın mekânsal incelemesinin yapılmasını konu edinmiştir. Bunun gerçekleştirilebilmesi için de üzerinde hala çalışılan ve belirli aralıklarla güncellemeler yapılan, açık kaynak kodlu, mekan dizimi analizi yapabilen, uzaysal analiz yazılımlı bir program olan Space Syntax depthMapX verileri üzerine kurgulanmıştır (URL-1). Kentsel ölçekte çalışabilmesi ve kent içindeki elemanların her birinin kendi aralarındaki ilişkilerini test edebilen bir sanal beyin olması nedeniyle tercih edilmiş, çıktı olarak sunduğu grafik ağ analizleri çalışmada kullanılmıştır.

Yerinde yapılan alan incelemeleri ile program verileri çakıştırılarak, araştırılan kent meydanının tanımlamasının daha doğru yapılacağı düşünülmüştür. Bu sayede uygulanan yöntem, bireysel kullanıcı açısından, kamusal mekan algısının tespit edilmesine destek olmuştur.

\subsection{Eksenel Harita}

Sayısal veri hesaplamaları için öncelikle Space Syntax depthMapX programı ile meydanın eksenel haritası (Axial Map) çıkartılmıştır. Bu harita ile iki boyutlu veri analizi yapılmaktadır. Eksenel harita çalışmasında, programın arayüzünde yer alan Bağlantı (Connectivity), Yoğunluk (Intensity), Bütünleşme (Integration) ve Dağıntı (Entropy) başlıkları, çalışmanın ana fikrindeki 'meydan' kavramıyla ilişkili görüldüğü için değerlendirmeye alınmıştır. Değerlendirmeler sonucu dört ayrı harita katmanı elde edilmiştir. Ortaya çıkan haritalar, çizgilerin oluşturduğu bir ağ örüntüsüne benzemektedir. Oluşturulan bu katmanların, program tarafından ayrıca sayısallaştırılması da yapılmakta, girdi olarak sunulan kentsel mekanın farklı yönlerden değerlendirilmesi mümkün kılınmaktadır. Çalışmada elde edilen bu sayısal değerler de ayrıca sunulmuştur.

Eksenel bir harita, alanın tamamını kaplayacak şekilde iki köşenin konveks ve konkav çizgiler çizilerek birleştirilmesiyle oluşturulmaktadır. $\mathrm{Bu}$ çizgiler, programın algoritmasına göre yap1 adalarının arasında kalan boşluğun soyutlanması olarak tanımlanmaktadır. Böylece kullanıcının belirlediği kent alanının mekânsal biçimi hesaplanabilir hale gelmektedir (Ariza-Villaverde ve ark., 2013). 


\subsection{Görünürlük Grafik Analizi}

Eksenel harita çalışmasının tamamlanmasının ardından alanın görünürlük grafik analizi (Visual Graphic Analysis - VGA) de çıkartılmıştır. Bu harita üç boyutlu bir bakış açısını hedef almakta ve mekan içerisinde kullanıcının görüşünü engelleyen her objenin haritaya işlenerek, alanın insan görüşü üzerine taramasını yapmaktadır. Bu noktada haritaya ağaç, heykel, direk, yapı gibi yüksekliği fazla olan objeler eklenmiş olup, çalılık, bank gibi görüşü engellemeyen objeler eklenmemiştir.

Görünürlük grafik analizi, eksenel haritada olduğu gibi hareket kalıplarıyla tanımlanmamakta, mevcuttaki düzenin kendi içindeki ilişkisel bağıntılarını hesaplamaktadır. Çevre tasarımına katkı sağlaması için geliştirilen program, çeşitli birimlerin birlikte görünebilirliğini hesaplar ve bu ilişkileri temsil etmek için bir matris üretir (Turner, 2001).

\section{Mekan Dizim Analizinin Bir Mekan Olarak 'Meydan' Kavramına Katkıları: Karabük Kent Meydanı}

Karabük Kent Meydanı, Merkez ilçesinde yer alması ve şehir girişine yakın olması gibi özelliklerinden dolayı 'görünebilirliği' ve kentlinin kullanım potansiyelinin yüksek olarak değerlendirilebileceği bir konumda yer almaktadır. Bu özelliklerine rağmen, üç taraftan karayolları ile sınırlandırılmış olması, diğer taraftan da devlet arazisiyle komşu olması nedeniyle kentten kopuk olduğu söylenebilmektedir. Meydanın farklı kotlarla kademelenmiş olması, kotlar arası geçişlerin merdivenli uygulanması ise kentlinin bu alanı geçiş mekanı olarak da tercih etmemesinin sebeplerindendir. Ayrıca yeşil alan azlığı ve mevsimsel etkenlerden insanı koruyamayan yapısı ile kentlinin kendine uygun bir yer bulmasına, isteğe bağlı aktiviteleri gerçekleştirmesine engel olmaktadir.

Alan çalışmasıyla tespit edilebilen, deneyime dayalı ve görsel olarak desteklenebilen veriler haricinde, Karabük Kent Meydanı için Space Syntax depthMap X programı ile mekan dizim analizleri de yapılmıştır. Program, kent bölgesinde yer alan ulaşım hatlarına çizgiler çizerek, bu çizgiler kümesinin aracılığıyla alandaki uzamsal tanımını yapmaktadır. Analiz sınırları olarak, incelenen meydanın merkezde yer alacağ $1 \mathrm{~km}^{2}$ 'lik bir alan belirlenmiştir. Bu kapsamda öncelikle alanın eksenel haritası çıkartılmış, kent bölgesinin yorumlanması için de dört parametre tercih edilmiştir: bağlantısallık, bütünleşme, yoğunluk ve dağıntı. 
Bağlantısallık (Connectivity) haritasına bakıldığında (Şekil 3), Karabük Kent Meydanı çevresinde ağırlıklı olarak turuncu ve sarı renklerin olduğu görülmektedir. Kırmızı rengin görüldüğü cadde de meydana ulaşan birincil ulaşım hatlarından birisidir. Meydanın güneyinde yer alan Zonguldak yolu üzerinde görülen renkler de açık yeşil ve sarı ağırlıklıdır. Meydana ulaşan ikincil ulaşım hatlarındaki renkler artık açık mavi, mavi ve mor gibi bağlantısallık değerleri düşük yollar olarak karşımıza çıkmaktadır.

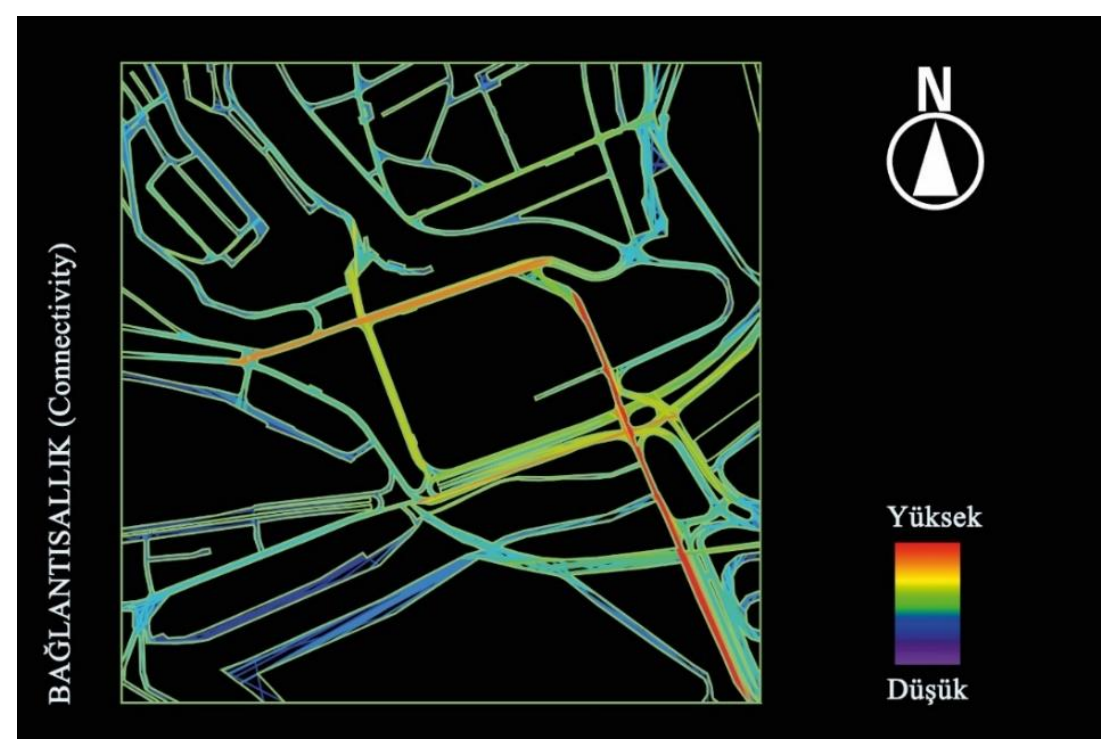

Şekil 3. Bağlantısallık haritası

Bütünleşme (Integration) haritasında ise (Şekil 4), meydanın etrafında kırmızı renginin yoğun olarak yer aldığı ve yanında turuncu ile sarı renklerinin de meydanı çevrelediği görülmektedir. Meydana yakın çevredeki diğer ulaşım hatlarının da sarı ve turuncu renklerle çevrelenmektedir. Bütünleşme değerinin üçüncül ulaşım hatlarında düşüşte olduğu söylenebilmekte olsa da bu bölgelerde mavi ya da mor yerine yine de açık yeşil ve koyu yeşil gibi renklerin bulunması meydanın çevresiyle ilişkisi açısından önemli bir veri olarak karşımıza çıkmaktadır. Yoğunluk (Intensity) haritası da (Şekil 5) Bütünleşme haritasına benzer değerlere sahiptir. Karabük Kent Meydanı ve çevresi aynı şekilde kırmızı, turuncu ve sarı renkli ulaşım hatları ile çevrelenmiştir. 


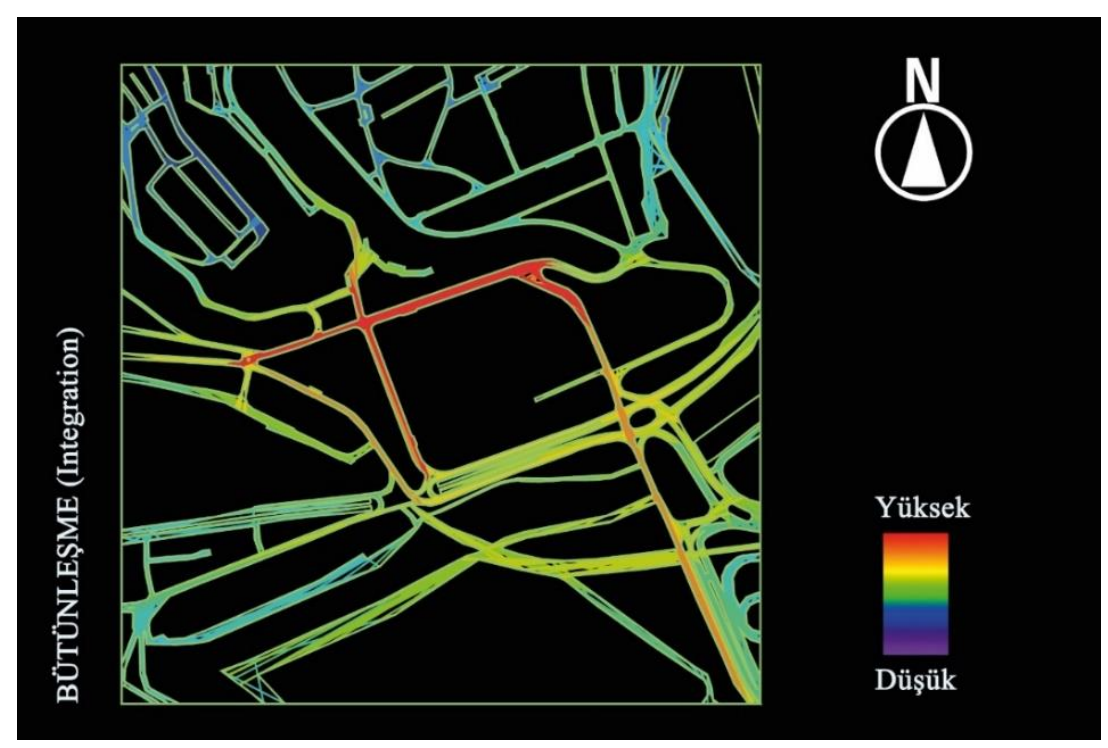

Şekil 4. Bütünleşme haritası

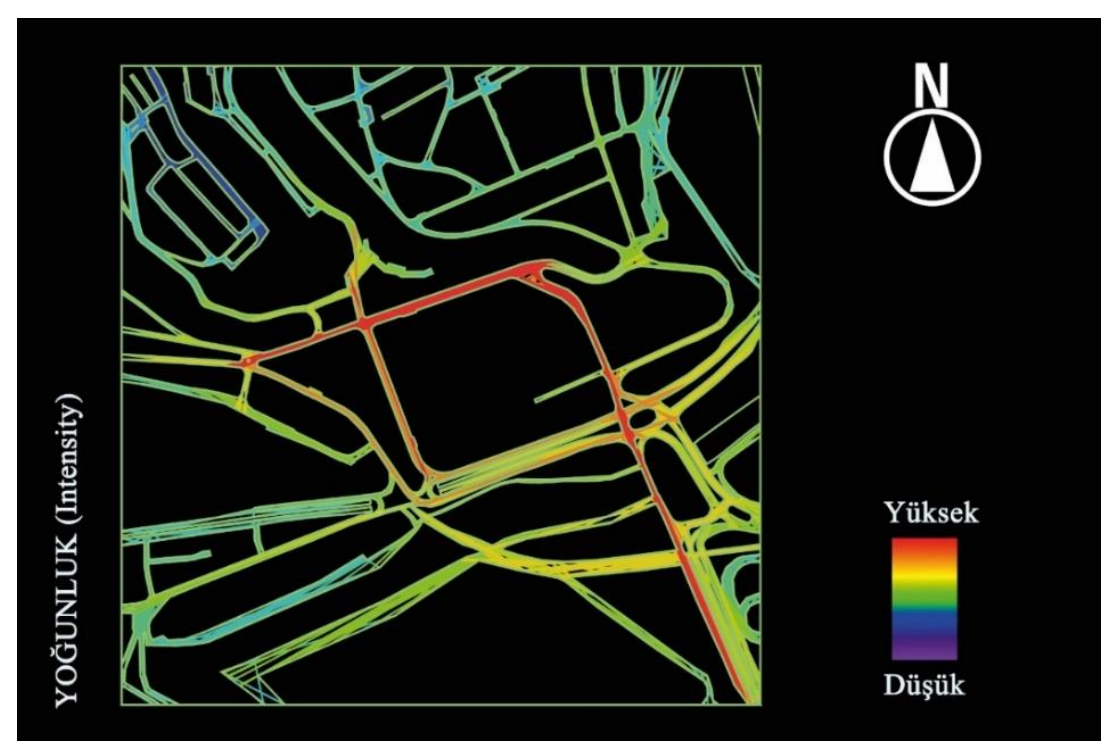

Şekil 5. Yoğunluk haritası

Dağıntı (Entropy) haritasına geldiğimizde de (Şekil 6), meydanın özellikle kuzey ve batı yönlerinde bulunan ulaşım hatlarının yoğunlukla koyu mavi renkli olduğu görülmektedir. Meydana ulaşan birincil ve ikincil ulaşım hatlarının da açık mavi ve yeşil tonlarında devam etmektedir. Meydanla ilişkisinin direkt olmadığı, uzak olarak tanımlanabilecek diğer ulaşım hatlarında turuncu ve kırmızıların olduğu ulaşım hatları bulunmaktadır. Diğer üç haritanın tersine, Dağıntı haritasında meydan ve çevresindeki renk dağılımının lejand değerindeki düşük seviyeye daha yakın olması olumlu bir çıktı olarak değerlendirilmektedir. 


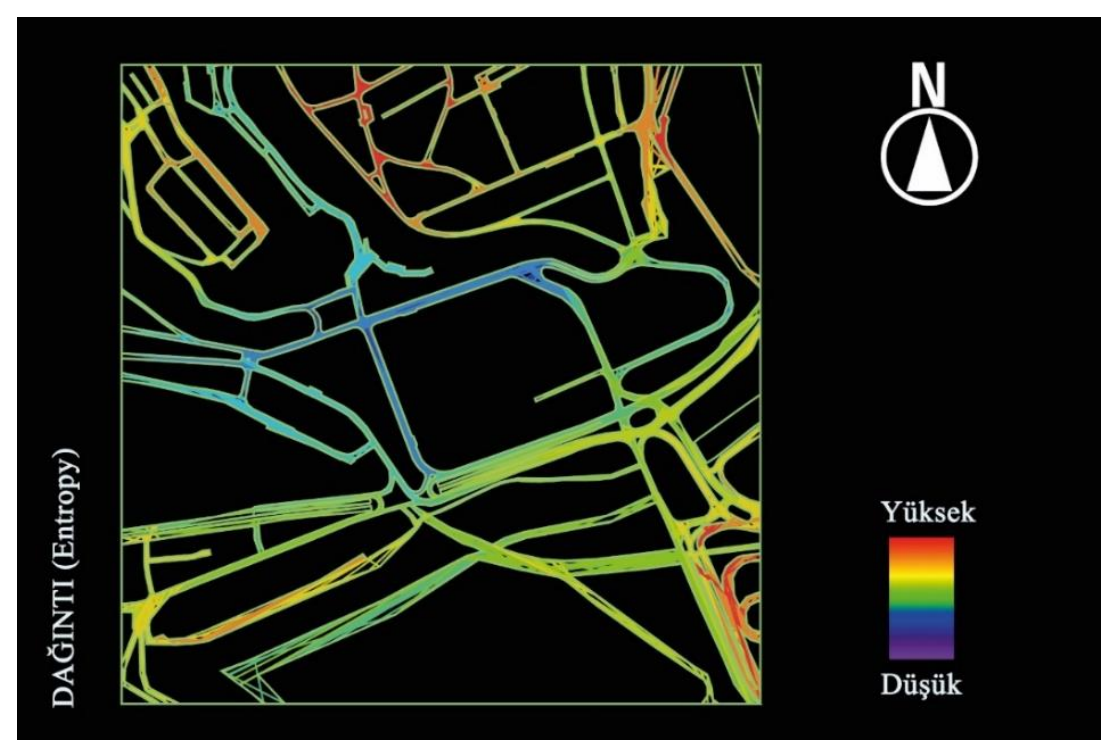

Şekil 6. Dağıntı haritası

Eksenel harita çalışmasından sonra Görünürlük Grafik Analizi yapılmıştır. Bu çalışma için alanın öncelikle gridleri bölünmesi gerekmektedir. Grid boyutları, çalışmanın amacına uygun olacak şekilde kullanıcının belirlediği değerle oluşturulmaktadır. Karabük Kent Meydanı üzerinde yapılan bu araştırmada grid boyutu, insan ölçeği referans alınarak $70 \mathrm{~cm}$ olarak belirlenmiştir. Haritada görüş açısını engelleyen objelerin yerleri gösterilmiş, geriye kalan boşlukla ilgili hesabın yapılması için de açıklık alanlar boyanmaktadır.

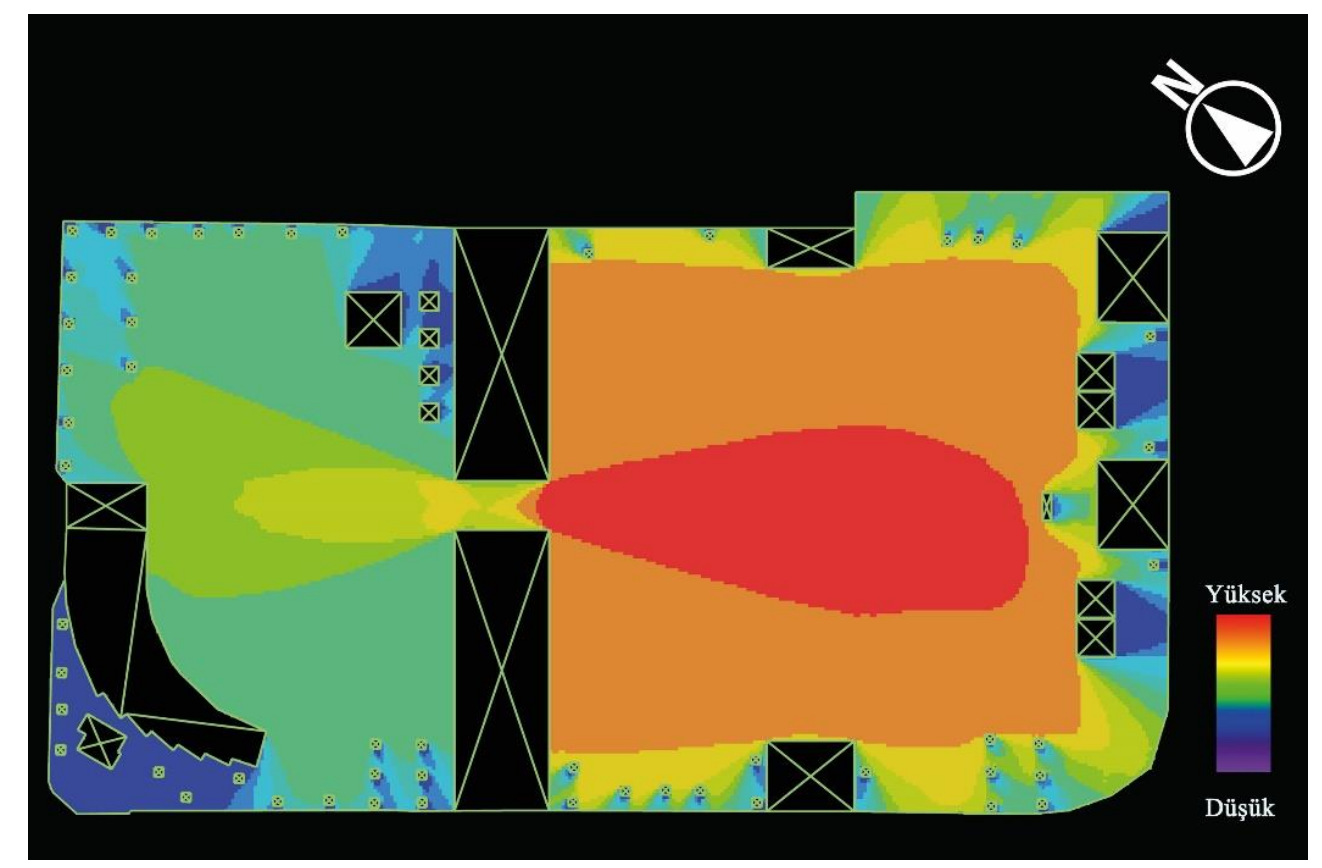

Şekil 7. Görünürlük Grafik Analizi 
Gezer, M.S., ve Qurraie, B.S., Uluslararası Doğu Anadolu Fen Mühendislik ve Tasarım Dergisi / International Journal of Eastern Anatolia Science Engineering and Design (IJEASED)

(2021) 3(1):43-54

Görünürlük Grafik Analizi (VGA) haritasında (Şekil 7), alt kotta yer alan meydan kısmının ortalarında yoğun bir kırmızı rengi görülmektedir. Tonlar bu kotta meydanın çeperlerine doğru açılmış, ağaç, heykel, pergola gibi elemanların olduğu yerlerde mavi ve mor tonlarına dönmüştür (Şekil 8). Üst kotta yer alan kısımda ise, engellerin boyutu ve miktarı arttığı için renk skalasındaki yüksek değerleri gösteren kırmızı ya da turuncu renkleri burada yer almamaktadır. Sarı ve açık yeşilden başlayan tonlar, yine burada da çeperlere doğru koyulaşmaya başlamıştır.
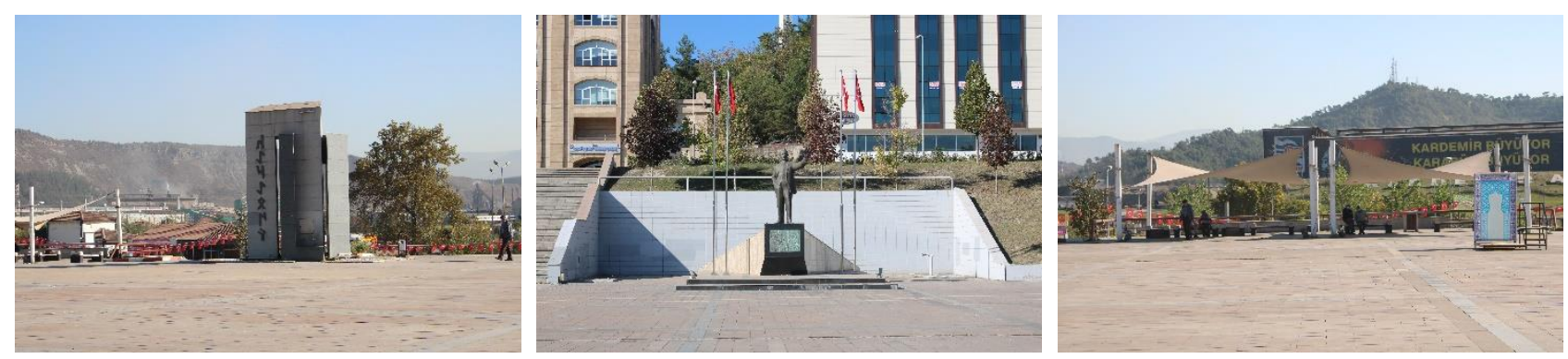

Şekil 8. Çalışma alanından heykel ve pergola örnekleri

\section{Sonuç ve Değerlendirme}

Çalışma kapsamında Karabük ili Merkez ilçesinde yer alan Karabük Kent Meydanı, Space Syntax depthMapX programı kullanılarak analiz edilmiştir. Bu meydan, Karabük Demir-Çelik Fabrikaları'na bağlı konut yerleşkelerinden biri olan 100 Evler'in yıkılmasıyla ortaya çıkan kentsel boşluğa inşa edilmiştir. Yıkımına 2010 yılında başlanmış olan yerleşkenin eski fotoğraflarında yoğun bir yeşil alana sahip olduğu görülmekte olup (Şekil 9), planlanan meydan park projesinin de yine yeşil ağırlıklı olacağı duyurulmuştur (URL-2).

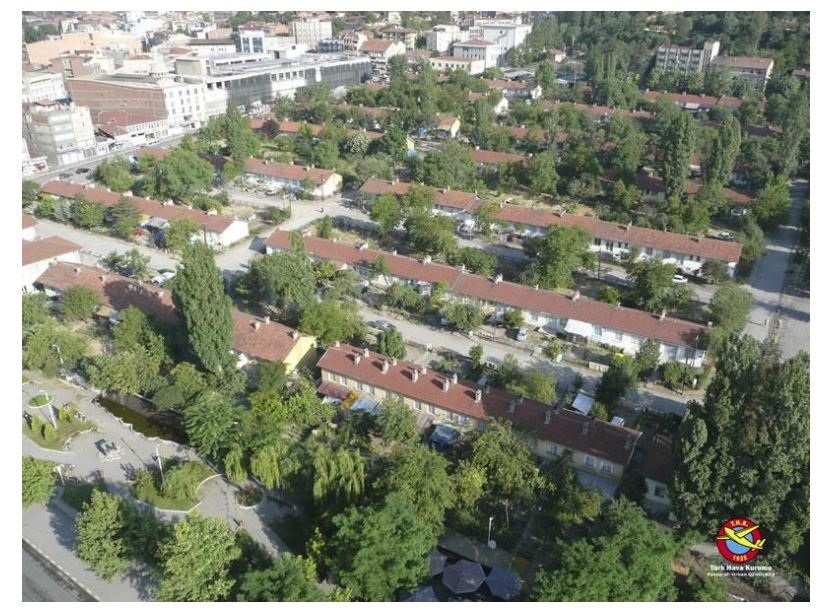

Şekil 9. 100 Evler'in yıkılmadan önce çekilmiş hava fotoğrafi (URL-2) 
Meydan kelimesinin tanımsal alt yapısında bulunan kamusal olma, toplanma alanı olarak kullanılma, anıtsallık, çevrelenme gibi parametreler bağlamında Karabük Kent Meydanı incelendiğinde, bu kavramlara karşılık verebilecek bir meydan olmadığı söylenebilmektedir. Halbuki meydanın 2014 yılından itibaren kullanıma açılmış, 14 Mayıs 2015 tarihinde de resmi açılışının gerçekleştirilmiş olması, bu kavramlara karşılık gelebilen daha işlevsel bir 'yeni' meydan olması konusunda beklenti yaratmıştır.

Program çıktıları sonucunda ulaşım hatları açısından meydanın konumu ve yerleşmesinin mantıklı bir karar olduğu söylenebilir. Meydan ve çevresinin Bağlantısallık haritası sonuçlarına göre, tüm ana yolları kendine bağlayan bir konumda olduğu görülmektedir. Bütünleşme ve Yoğunluk haritalarında bu parametrelerle ilgili renk yoğunluğunun yüksek değerlerinin daha fazla olması, 'meydan' kavramının ihtiyacı olan bir araya getirme, toplanma kavramlarının bu alan için iki boyutlu olarak yeterli olduğunu göstermektedir. Dağıntı analizinde ise, bu çevrede bu etkinin düşük olarak çıkması, yine meydanın konumunun belirlenmesinde alınan kararın doğruluğunu desteleyecek şekildedir.

Görünürlük Grafik Analiz sonuçlarına bakıldığındaysa, meydanın işlevsel olmadığı, görüşü engelleyen bir sürü obje ya da elemanın olduğu ortaya çıkmaktadır. Kademeli bir alan olması da yine bu görüş engellerinin en büyük sebeplerindendir. Orta kademede yer alan nikah salonu ve birkaç dükkana rağmen, insan yoğunluğu gün içinde fazla olmamaktadır. Çünkü bu mekanlar için gelen kullanıcı da meydanın tamamına görsel olarak hakim olamamakta, işi bittikten sonra mekanı terk etmekte ya da işi harici hiç uğramamaktadır.

Alanın geçmişte sahip olduğu yeşil alan oranı ve çok yıllık ağaç sayısı ile günümüzdeki değerleri kıyas bile gerektirmeyecek derecede üzücüdür. Bir 'meydan' için, 'boşaltma' işleminin yapılması gerekli görülse de farklı çözüm yollarının aranmadan, yalnızca ‘yıkım’ yönteminin tercih edilmesi üzerine düşünülmesi ve tartışılması gereken bir konudur.

\section{Yazarların Katkısı}

Çalışmada her iki yazar da eşit oranda katkı sunmuştur.

\section{Çıkar Çatışması Beyanı}

Yazarlar arasında herhangi bir çıkar çatışması bulunmamaktadır.

\section{Araştırma ve Yayın Etiği Beyanı}

Yapılan çalışmada, araştırma ve yayın etiğine uyulmuştur. 
Gezer, M.S., ve Qurraie, B.S., Uluslararası Doğu Anadolu Fen Mühendislik ve Tasarım Dergisi / International Journal of Eastern Anatolia Science Engineering and Design (IJEASED)

(2021) 3(1):43-54

\section{Teșekkür}

Bu çalışmanın özet bildirimi “18-21 Kasım 2020’de Karabük Üniversitesi, Mimarlık Fakültesi tarafından Safranbolu'da Uluslararası Mimarlık Araştırmaları Sempozyumu (ReseArch'20)" kongresinde sözlü sunum olarak sunulmuş olup, kongre üyelerine teşekkür ederiz.

\section{Kaynaklar}

Ariza-Villaverde, A.B., Jimenez-Hornero, F.J., Gutierrez de Rave, E., (2013). Multifractal analysis of axial maps applied to the study of urban morphology. Journal of Computers, Environment and Urban Systems, 38, 3-10.

Fındıkoğlu, Z. F. (1960). Karabük'ün Teşekkülü ve Bazı Demografik ve İktisadi Meseleler, Sosyoloji Konferansları Dergisi, 1(1), 1-10.

Hasol, D. (2017). Ansiklopedik Mimarlı Sözlüğü, İstanbul: Yap1-Endüstri Merkezi Yayınları.

Kalyoncu, H. (2016). Zaman, Mekan ve Anılarla Karabük, Karabük: Kardemir AŞ Yayınları.

Kütükçüoğlu, M. (2012). Türkiye’nin İlk A ğır Sanayi Kenti Karabük, Karabük: Karabük Valiliği Yayınları.

Ulutaş, E. (2019). İmgeden Gerçekliğe: Kamusal Bir Mekan Olarak Meydan, İçtimaiyat Sosyal Bilimler Dergisi, 3(2), 138-146.

Turner, A., (2001). Depthmap: A Program to Perform Visibility Graph Analysis. 3rd International Symposium on Space Syntax (31.1-31.9). Atlanta: Georgia Institute of Technology.

URL-1: UCL: The Bartlett Scholl of Architecture, www.ucl.ac.uk/bartlett/architecture/research/spacesyntax/depthmapx (Erişim tarihi: 15.06.2020).

URL-2: https://www.karabuk.bel.tr/haber.asp?id=646 (Erişim tarihi: 08.10.2020). 